\title{
openheart Twelve-month outcome in patients with stroke and atrial fibrillation not suitable to oral anticoagulant strategy: the WATCH-AF registry
}

\author{
Celine Guidoux, ${ }^{1}$ Elena Meseguer ${ }^{1}$ Elodie Ong, ${ }^{2}$ Philippa C Lavallée, ${ }^{1}$ \\ Cristina Hobeanu, ${ }^{1}$ Linsay Monteiro-Tavares, ${ }^{1}$ Hugo Charles, ${ }^{1}$ Lucie Cabrejo, ${ }^{1}$ \\ Anna Martin-Bechet, ${ }^{1}$ Ricardo Rigual, ${ }^{1}$ Norbert Nighoghossian, ${ }^{2}$ \\ Pierre Amarenco (iD ${ }^{1}$
}

\begin{abstract}
- Additional material is published online only. To view please visit the journal online (http://dx.doi.org/10.1136/ openhrt-2019-001187)

To cite: Guidoux C, Meseguer E, Ong $\mathrm{E}$, et al. Twelve-month outcome in patients with stroke and atrial fibrillation not suitable to oral anticoagulant strategy: the WATCH-AF registry. Open Heart 2019;6:e01187. doi:10.1136/ openhrt-2019-001187
\end{abstract}

Received 10 0ctober 2019 Revised 7 November 2019 Accepted 18 November 2019

Check for updates

(C) Author(s) (or their employer(s)) 2019. Re-use permitted under CC BY-NC. No commercial re-use. See rights and permissions. Published by BMJ.

${ }^{1}$ Department of Neurology and Stroke center, Paris Univesity, Paris, France

${ }^{2}$ Department of Neurology and Stroke center, Centre Hospitalier Universitaire de Lyon, Lyon, France

Correspondence to Dr Pierre Amarenco; pierre. amarenco@aphp.fr

\section{ABSTRACT}

Aims Long-term oral anticoagulant (LTOAC) reduces ischaemic stroke recurrences. Because of bleeding history, frailty, cognitive impairment, comorbidities or patient refusal, many cannot be discharged from stroke unit on LTOAC. Proportion and outcome of these patients is not well known.

Methods The Warfarin Aspirin Ten-a inhibitor Cerebral infarction and Haemorrhage and atrial fibrillation (AF) prospective registry enrolled consecutive patients with an acute stroke associated with AF. Scales to evaluate stroke severity, disability, functional independence, cognition, risk of fall, ischaemic and haemorrhagic risk stratification were systematically collected at admission, discharge, 3 and 12 months poststroke. The two main 12-month endpoints were death or dependency (modified Rankin Scale $>3$ ) and recurrent stroke.

Results Among 400 patients (370 brain infarctions, 30 brain haemorrhages), 274 were discharged on LTOAC, 31 died before discharge and 95 (24\%) were not discharge on anticoagulant (frailty, bedridden or demented, EHRA/ESC contraindication to anticoagulant). Death or dependency and recurrent stroke occurred in $19.8 \%$ and $9.9 \%$, respectively, in patient on anticoagulant, and $33.5 \%$ and $27.2 \%$ in those not on anticoagulant (both $p<0.001$ ). Patient not anticoagulated at discharge had a 1.6-fold increase in the risk of death or dependency at 12 months (HR 1.65; 95\% Cl 1.05 to $2.61 ; p=0.032$ ) and a 2.5 -fold increase in the risk of stroke (HR $2.46 ; 95 \% \mathrm{Cl} 1.36$ to $4.44 ; \mathrm{p}=0.003)$.

Conclusions One-fourth of patients with stroke associated with AF are not discharged on anticoagulation and have a dramatic increase in the risk of death or dependency at 12 months as well as recurrent stroke. Alternative treatments should be trialled in these patients.

\section{INTRODUCTION}

Patients admitted to hospital with stroke and atrial fibrillation (AF) (known before or discovered at admission) have a high risk of death, dependency and recurrent stroke. ${ }^{1-4}$ The treatment of choice to prevent another ischaemic stroke is a long-term oral anticoagulant strategy. ${ }^{5}{ }^{6}$ However, many of these patients cannot be on oral anticoagulant because of contraindication to long-term oral anticoagulant, comorbidity, frailty, cognitive impairment, severe walking difficulties with frequent falls and patient refusal. ${ }^{2}$ The proportion of these patients among patients presenting with a stroke and $\mathrm{AF}$ in stroke units is not precisely known.

The risk of death or dependency as well as the risk of recurrent stroke in this group is not well known either. Given that recent alternative treatment to long-term oral anticoagulant has been proposed, such as left atrial appendage closure, ${ }^{78}$ we designed the Warfarin Aspirin Ten-a inhibitor Cerebral infarction and Haemorrhage and AF (WATCH-AF) prospective registry in which we collected consecutive patients admitted with an acute stroke within 72 hours of symptom onset in two busy stroke centres with thorough evaluation regarding risk stratification $\left(\mathrm{CHA}_{2} \mathrm{DS}_{2} \mathrm{VASc}\right.$, HAS-BLED, ATRIA scores), stroke severity, disability and functions (NIHSS, Rankin score, independent activity of daily living (IADL), Mini-Mental Status), risk of fall (STRATIFY score) as well as glomerular filtration rate, international normalised ratio (INR) and time in therapeutic range (TTR) while on vitamin $\mathrm{K}$ antagonist (VKA) before stroke. Based on these scores, we aimed to evaluate the proportion of patients not on a long-term oral anticoagulant after discharge from the stroke unit and during a 1-year follow-up. We also evaluated the 1-year risk of death or dependency, and of recurrent brain infarction/brain haemorrhage. 
Table 1 Baseline characteristics according to treatment groups

\begin{tabular}{|c|c|c|c|c|}
\hline & All $(n=400)$ & $\begin{array}{l}\text { Dead before } \\
\text { discharge }(n=31)\end{array}$ & LTOAC $(n=274)$ & No LTOAC ( $n=95)$ \\
\hline Age, mean (SD), years & $78.7(11.0)$ & $83.8(7.2)$ & $78.1(11.4)$ & $78.7(10.6)$ \\
\hline Men & $193(48.3)$ & $12(38.7)$ & $122(44.5)$ & $59(62.1)$ \\
\hline \multicolumn{5}{|l|}{ Medical history } \\
\hline Hypertension & $317(79.3)$ & $20(64.5)$ & 216 (78.8) & $81(85.3)$ \\
\hline Diabetes & $87(21.8)$ & $11(35.5)$ & $49(17.9)$ & $27(28.4)$ \\
\hline Dyslipidaemia & $168(42.0)$ & $10(32.3)$ & $119(43.4)$ & $39(41.1)$ \\
\hline Former smokers & $116(30.1)$ & $5(17.2)$ & $83(31.4)$ & $28(30.4)$ \\
\hline Current smokers & $32(8.3)$ & $1(3.4)$ & $22(8.3)$ & $9(9.8)$ \\
\hline Regular alcohol consumption & $42(10.6)$ & $1(3.7)$ & $29(10.6)$ & $12(12.6)$ \\
\hline Cerebrovascular disease & $89(22.3)$ & $5(16.1)$ & $62(22.7)$ & $22(23.2)$ \\
\hline Coronary artery disease & $68(17.0)$ & $5(16.1)$ & $42(15.4)$ & $21(22.1)$ \\
\hline Peripheral artery disease & $30(7.5)$ & $0(0)$ & $20(7.3)$ & $10(10.5)$ \\
\hline Congestive heart failure & $53(13.3)$ & $4(12.9)$ & $32(11.7)$ & $17(17.9)$ \\
\hline $\begin{array}{l}\text { Significant valvular disease or } \\
\text { prosthetic heart valves }\end{array}$ & $38(9.5)$ & $2(6.5)$ & $31(11.4)$ & $5(5.3)$ \\
\hline \multicolumn{5}{|l|}{ Type of stroke } \\
\hline TIA & $35(8.8)$ & $0(0)$ & $28(10.2)$ & $7(7.4)$ \\
\hline Ischaemic stroke & $335(83.8)$ & $26(83.9)$ & $240(87.6)$ & $69(72.6)$ \\
\hline Intracerebral haemorrhage & $27(6.8)$ & $5(16.1)$ & $5(1.8)$ & $17(17.9)$ \\
\hline Subdural haematoma & $2(0.5)$ & $0(0)$ & $1(0.4)$ & $1(1.1)$ \\
\hline Subarachnoid haemorrhage & $1(0.3)$ & $0(0)$ & $0(0)$ & $1(1.1)$ \\
\hline \multicolumn{5}{|l|}{ Baseline NIHSS } \\
\hline 0 & $65(16.4)$ & $0(0)$ & $50(18.5)$ & $15(15.8)$ \\
\hline $1-4$ & $111(28.0)$ & $2(6.7)$ & $83(30.6)$ & $26(27.4)$ \\
\hline $5-9$ & 76 (19.2) & $3(10.0)$ & $60(22.1)$ & $13(13.7)$ \\
\hline $10-20$ & $102(25.8)$ & $16(53.3)$ & $56(20.7)$ & $30(31.6)$ \\
\hline$\geq 21$ & $42(10.6)$ & $9(30.0)$ & $22(8.1)$ & $11(11.6)$ \\
\hline \multicolumn{5}{|l|}{ Examinations } \\
\hline BMI, mean (SD), kg/m² & $25.6(5.0)$ & $24.9(4.3)$ & $25.5(5.0)$ & $26.1(5.3)$ \\
\hline Systolic BP, mean (SD), mm Hg & $148.7(26.0)$ & $145.3(27.4)$ & $146.0(23.6)$ & $157.8(30.3)$ \\
\hline Diastolic BP, mean (SD), mm Hg & $78.4(15.6)$ & $76.5(17.5)$ & $77.6(14.5)$ & $81.4(17.7)$ \\
\hline Glucose, median (IQR), mg/dL & $106.0(93.0-133.0)$ & $118.0(107.0-142.0)$ & $104.0(93.0-129.0)$ & $113.0(96.0-142.0)$ \\
\hline Haemoglobin A1C, median (IQR),\% & $5.9(5.6-6.5)$ & $6.1(5.7-6.9)$ & $5.9(5.6-6.4)$ & $6.0(5.6-7.0)$ \\
\hline Creatinine, median (IQR) umol/L & $86.5(71.0-110.5)$ & $93.0(70.0-118.0)$ & $82.0(70.0-102.0)$ & $92.0(74.0-119.0)$ \\
\hline $\begin{array}{l}\text { INR, mean (SD) (patients on VKA only) } \\
\text { before baseline }\end{array}$ & $2.3(0.6)$ & $2.3(1.0)$ & $2.3(0.6)$ & $2.3(0.5)$ \\
\hline$<2$ & $20(34.5)$ & $1(33.3)$ & $13(36.1)$ & $6(31.6)$ \\
\hline$\geq 2$ and $\leq 3$ & $38(65.5)$ & $2(66.7)$ & $23(63.9)$ & $13(68.4)$ \\
\hline $\begin{array}{l}\text { Time-in-therapeutic range (pts on } \\
\text { VKA), median \% (IQR) before baseline }\end{array}$ & $62.5(50.0-85.7)$ & $53.6(50.0-61.9)$ & $62.5(50.0-100.0)$ & $66.7(33.3-85.7)$ \\
\hline$<50 \%$ & $15(24.6)$ & $0(0)$ & $9(23.7)$ & $6(31.6)$ \\
\hline $50 \%-59 \%$ & $13(21.3)$ & $3(75.0)$ & $8(21.1)$ & $2(10.5)$ \\
\hline $60 \%-69 \%$ & $7(11.5)$ & $1(25.0)$ & $4(10.5)$ & $2(10.5)$ \\
\hline$\geq 70 \%$ & $26(42.6)$ & $0(0)$ & $17(44.7)$ & $9(47.4)$ \\
\hline
\end{tabular}


Table 1 Continued

\begin{tabular}{|c|c|c|c|c|}
\hline & All $(n=400)$ & $\begin{array}{l}\text { Dead before } \\
\text { discharge }(n=31)\end{array}$ & LTOAC $(n=274)$ & No LTOAC (n=95) \\
\hline $\begin{array}{l}\text { Glomerular filtration rate, median } \\
(\mathrm{IQR}), \mathrm{mL} / \mathrm{min} / 1.73^{2}\end{array}$ & $65.1(49.3-81.0)$ & $52.4(37.0-75.4)$ & $67.0(52.6-83.5)$ & $60.0(43.4-76.8)$ \\
\hline$<30$ & $26(6.5)$ & 4 (12.9) & $14(5.1)$ & $8(8.4)$ \\
\hline $30-59$ & $143(35.8)$ & $13(41.9)$ & $91(33.2)$ & $39(41.1)$ \\
\hline Haemoglobin, mean (SD), g/L & $13.4(1.8)$ & $13.1(2.0)$ & $13.5(1.7)$ & $13.3(2.0)$ \\
\hline \multicolumn{5}{|l|}{ Medication at discharge } \\
\hline Antiplatelet & $72(18.1)$ & - & $37(13.6)$ & $28(29.5)$ \\
\hline $\begin{array}{l}\text { Anticoagulant (both long term and very } \\
\text { short term) }\end{array}$ & $294(73.7)$ & - & $244(89.4)$ & $45(47.4)^{\star}$ \\
\hline Anticoagulant+antiplatelet & $24(6.0)$ & - & $19(7.8)$ & $4(8.9)^{\star}$ \\
\hline BP lowering therapy & $368(92.0)$ & - & $255(93.1)$ & $93(97.9)$ \\
\hline Lipid-lowering therapy & $284(71.0)$ & - & $212(77.4)$ & $62(65.3)$ \\
\hline Glycaemia lowering therapy & $87(21.8)$ & - & $52(19.0)$ & $26(27.4)$ \\
\hline
\end{tabular}

* Short-term anticoagulant.

BMI, body mass index; BP, blood pressure; INR, international normalised ratio; LTOAC, long-term oral anticoagulant; NOAC, new oral anticoagulant; TIA, transient ischaemic attack; VKA, vitamin $\mathrm{K}$ antagonist.

\section{MATERIAL AND METHODS}

Study subjects were consecutive stroke patients with $\mathrm{AF}$ admitted to the Bichat Stroke Centre and the Lyon Stroke Unit. Inclusion criteria were ischaemic or haemorrhagical stroke as well as transient ischaemic attack associated with AF hospitalised in both stroke unit within 72 hours of stroke onset. AF could be diagnosed before the stroke, at admission or up to 30 days after the stroke. Inclusions were prospective, consecutive and exhaustive during the accrual period, with verification that all patients with AF have been included. We had no exclusion criteria. Patients were then followed for 1 year. At the time of accrual, these two busy stroke centres had limited access to left atrial appendage closure facilities. Informed consent has been obtained from the subjects (or their legally authorised representative).

Clinical data 1 and 6 months before stroke were recorded, including: prestroke antiarrhythmic and antithrombotic treatments, prestroke AF stroke risk scales $\left(\mathrm{CHA}_{2} \mathrm{DS}_{2}\right.$-VASC, ATRIA haemorrhage score, HASBLED) and pre-stroke functional scores (Rankin score evaluating disability, IADL- evaluating functional independence and STRATIFY Risk Assessment Tool, evaluating the risk of fall). In case the patient was not under anticoagulant, the treating physician was interviewed to understand the reasons. If the patient was under VKA, prestroke INR values over the 6 months before were collected.

During the hospitalisation, data collected were: clinical demographics at baseline, medical history, antiarrhythmic and antithrombotic treatment. NIHSS was recorded at baseline. MRI was analysed (or CT, in case MRI was not performed). Other diagnostic tests collected were 12-lead ECG, continuous intrahospital cardiac monitoring (telemetry), Holter-EKG, transthoracic and transoesophageal echography, intracranial and extracranial artery assessment. If ischaemic stroke was diagnosed, the underlying causes were graded according to the ASCOD classification. ${ }^{9}{ }^{10}$ In case of haemorrhagic stroke, the aetiology was also recorded, as well as the number and topography of microbleeds. Treatment, including thrombolysis and thrombectomy, other antithrombotic drugs, blood pressure lowering, lipid-lowering and glycaemia lowering drugs, was recorded. NIHSS, modified Rankin Scale (mRS) score, STRATIFY risk assessment tool and MMS were evaluated at discharge.

Based on this assessment and on ESC/EHRA guidelines, ${ }^{11-13}$ for each patient, two vascular neurologists (EM, EO, CG, PA and Delphi method) discussed the preventive strategy at discharge. We then defined one group on a long-term oral anticoagulant strategy, one other not on a long-term oral anticoagulant strategy for various reasons (eg, patient refusal, contraindication to long-term oral anticoagulant, comorbidity, frailty, patient bedridden or with severe dementia, history of bleeding precluding a long-term oral anticoagulant strategy or adherence to treatment).

Follow-up was performed at 3 and 12 months by a vascular neurologist (EM, EO, CG, LC and PA) in a faceto-face visit or by phone call, in case the patient could 
Table 2 Clinical scores at discharge according to treatment groups: long-term oral anticoagulant strategy (LTOAC) versus not on an LTOAC (no LTOAC)

\begin{tabular}{|c|c|c|c|}
\hline & All $(n=400)$ & LTOAC $(n=274)$ & No LTOAC $(n=95)$ \\
\hline \multicolumn{4}{|l|}{ Discharge } \\
\hline Length of stay, days & $14.0(12.7)$ & $13.7(13.3)$ & $14.8(10.6)$ \\
\hline \multicolumn{4}{|l|}{ NIHSS } \\
\hline 0 & $109(29.6)$ & $87(31.8)$ & $22(23.4)$ \\
\hline $1-4$ & $141(38.3)$ & $113(41.2)$ & $28(29.8)$ \\
\hline $5-9$ & $53(14.4)$ & 35 (12.8) & $18(19.1)$ \\
\hline $10-20$ & $51(13.9)$ & $33(12.0)$ & $18(19.1)$ \\
\hline$\geq 21$ & $14(3.8)$ & $6(2.2)$ & $8(8.5)$ \\
\hline \multicolumn{4}{|l|}{ RANKIN } \\
\hline 0-1—no disability & $141(35.5)$ & $109(40.2)$ & $32(33.7)$ \\
\hline 2-3-needing some help & $132(33.2)$ & $106(39.1)$ & $26(27.4)$ \\
\hline 4-5-dependent or bedridden & $93(23.4)$ & $56(20.7)$ & $37(38.9)$ \\
\hline 6-death & $31(7.8)$ & $0(0)$ & $0(0)$ \\
\hline \multicolumn{4}{|l|}{ Stratify } \\
\hline 0 - low risk of fall & $242(68.0)$ & $182(68.7)$ & $60(65.9)$ \\
\hline 1-moderate risk of fall & $81(22.8)$ & $63(23.8)$ & $18(19.8)$ \\
\hline$\geq 2$ - high risk of fall & $33(9.3)$ & $20(7.5)$ & $13(14.3)$ \\
\hline \multicolumn{4}{|l|}{ MMSE } \\
\hline$\geq 30$ - cognition normal & $23(13.6)$ & $19(14.2)$ & $4(11.4)$ \\
\hline 25-30-mild cognitive impairment & $69(40.8)$ & $53(39.6)$ & $16(45.7)$ \\
\hline$\leq 24-$ moderate to severe cognitive impairment & $77(45.6)$ & $62(46.3)$ & $15(42.9)$ \\
\hline \multicolumn{4}{|l|}{ ASCOD } \\
\hline \multicolumn{4}{|l|}{ Atherothrombosis } \\
\hline A0—no atherosclerosis & $57(14.2)$ & $42(15.3)$ & $12(12.6)$ \\
\hline A3-atherosclerosis but not directly causal & $177(44.3)$ & $121(44.2)$ & $42(44.2)$ \\
\hline A2-ipsilateral atherosclerosis $<50 \%$ & $87(21.8)$ & $68(24.8)$ & $13(13.7)$ \\
\hline A1-ipsilateral atherosclerosis $>50 \%$ & $44(11.0)$ & $35(12.8)$ & $7(7.4)$ \\
\hline A9-insufficient workup to grade A & $35(8.7)$ & $8(2.9)$ & $21(22.1)$ \\
\hline \multicolumn{4}{|l|}{ Small vessel disease } \\
\hline So—no small vessel disease & $286(71.5)$ & $217(79.2)$ & $48(50.5)$ \\
\hline S30—severe leukoaraiosis, old lacune, microbleed & $53(13.3)$ & $35(12.8)$ & $16(16.9)$ \\
\hline S2-small deep infarct without old lacunes & $8(2.0)$ & $6(2.2)$ & $2(2.1)$ \\
\hline S1_-small deep infarct with old lacunes & $1(0.2)$ & $1(0.3)$ & $0(0)$ \\
\hline S9-insufficient workup to grade S & $52(13.0)$ & $15(5.5)$ & $29(30.5)$ \\
\hline \multicolumn{4}{|l|}{ Cardiac disease } \\
\hline C1—definite cardiac source of embolism & $367(91.7)$ & $265(96.7)$ & $76(80.0)$ \\
\hline C3-causally unrelated cardiac abnormality & $3(0.8)$ & $2(0.7)$ & $1(1.1)$ \\
\hline C9-insufficient workup to grade C & $30(7.5)$ & $7(2.6)$ & $18(18.9)$ \\
\hline
\end{tabular}

NIHSS, National Institute of Health Stroke Scale.

not come to the visit. Current place of residency, rehabilitation facilities, visit to healthcare physician and loss of productivity, if applicable, were recorded. Medication was collected as well as vital signs. Barthel Index, NIHSS, mRS, STRATIFY risk assessment tool and MMSE were performed at 3 and 12-month visits.
Main outcomes were death or dependency, and cerebrovascular recurrence (ischaemic or haemorrhagic); other outcomes were cardiac events, revascularisation procedure, major bleeding, aspiration pneumonia, deep venous thrombosis or pulmonary embolism, left atrial appendage closure and death. These outcomes were 
Table 3 Reasons for not being on a long-term oral anticoagulant strategy after discharge $(n=95)$

\begin{tabular}{|c|c|c|c|}
\hline Patient refusal & $2 / 95(2.1)$ & & \\
\hline Bleeding risk & $82 / 95(86.3)$ & & \\
\hline Previous haemorrhage & & $54 / 82(65.8)$ & \\
\hline Intracranial & & & $42 / 54(77.8)$ \\
\hline Gl bleed & & & $5 / 54(9.3)$ \\
\hline ENT & & & $1 / 54(1.9)$ \\
\hline Respiratory tract & & & $2 / 54(3.7)$ \\
\hline Superficial/haematoma & & & $3 / 54(5.6)$ \\
\hline Genitourinary tract & & & $4 / 54(7.4)$ \\
\hline Chronic anaemia & & & $2 / 54(3.7)$ \\
\hline Trauma & & & $4 / 54(7.4)$ \\
\hline Other & & & $2 / 54(3.7)$ \\
\hline $\begin{array}{l}\text { Never bleed but perceived } \\
\text { increased risk of bleeding }\end{array}$ & $d$ as at & 28/82 (34.1) & \\
\hline $\begin{array}{l}\text { Unobservant or perceived } \\
\text { as unobservant }\end{array}$ & $1 / 95(1.1)$ & & \\
\hline $\begin{array}{l}\text { Uncertainty about patient's } \\
\text { ability to understand } \\
\text { treatment* }^{\star}\end{array}$ & 6/95 (6.3) & & \\
\hline Others & $17 / 95(17.8)$ & & \\
\hline \multicolumn{2}{|c|}{ Chronic alcoholism or drug addiction } & & $0 / 17(0.0)$ \\
\hline \multicolumn{2}{|l|}{ Severe hepatic disease } & & $0 / 17(0.0)$ \\
\hline \multicolumn{2}{|c|}{ Specific contraindication to VKA } & & $0 / 17(0.0)$ \\
\hline \multicolumn{2}{|c|}{ Specific contraindication to NOAC } & & $1 / 17(5.8)$ \\
\hline \multicolumn{2}{|c|}{ Bedridden and cognitive deterioration } & & $16 / 17(94.1)$ \\
\hline
\end{tabular}

${ }^{\star}$ Cognitive deterioration, low level of education, not French speaking.

ENT, ear, nose, throat; NOAC, new oral anticoagulant; VKA, vitamin $\mathrm{K}$ antagonist.

collected during initial hospitalisation, at 3 months and 12 months

\section{Statistical analysis}

Quantitative variables were expressed as means $( \pm \mathrm{SD})$ in case of normal distribution or median (IQR) otherwise. Qualitative variables were expressed as counts (percentage).

Events rates were estimated at 12 months of follow-up from Kaplan-Meier estimates. Cumulative event curves were constructed using the Kaplan-Meier method. The 12-month event rates were compared according to treatment at discharge using the Cox proportional hazard model. For a given endpoint, deaths that were not included in the endpoint were treated as censoring events. Patients with no information at 12 months were treated as censored cases on the basis of the last follow-up available. Patients dead before discharge were not included in this analysis.

Univariate comparison between the primary outcome and brain infarction or brain haemorrhage and patient characteristics (ie, baseline demographics, risk factors, biological factors, main investigation findings and treatments) was done using the Student's t-test for continuous and the $\mathrm{X}^{2}$ test for qualitative variables. For variables with skewed distributions, Student's t-test was performed using log-transformed values.

All factors associated with the primary endpoint and brain infarction or brain haemorrhage in univariate analysis (at nominal $\mathrm{p}<0.10$ ) were implemented in a stepwise multiple Cox-regression analysis with an entry and removal values set to 0.10 . MMS score, ratio E/Eal, left atrium surface and aortic atheroma $\geq 4 \mathrm{~mm}$ were not considered candidate variables due to the high rate of missing data $(>25 \%)$. Owing to missing data on glucose, haemoglobin A1C, ejection fraction and pulmonary arterial pressure, multiple imputation of missing values by means of chained equations was done (10 imputed data sets were generated with the use of all patient characteristics described below).

For each imputed data, the complete model (ie, containing all significant factors with a $\mathrm{p}<0.10$ ) was implemented. Then the 10 estimates coefficients of each variable were combined and the least significant factor was removed from the model. The process was continued until the final model was obtained. The proportionalhazards assumption was verified with the use of Schoenfeld residuals.

All statistical tests were done at the two-tailed $\alpha$ level of 0.05 . All statistical analyses were generated using SAS V.9.3 for windows.

\section{RESULTS \\ Characteristics of patients}

A total of 400 patients were enrolled in the WATCH-AF registry. Per protocol, $300(75 \%)$ patients were included at the Bichat Stroke Centre (Paris) between 25 March 2014 and 10 April 2016 and 100 (25\%) at the Lyon Stroke Unit between 27 December 2015 and 14 May 2016, and followed 1year. Baseline characteristics of patients are presented in tables 1 and 2. A total of 370 patients $(92.5 \%)$ had an ischaemic stroke as qualifying event and 30 patients $(7.5 \%)$ had haemorrhagic stroke. Overall, the mean age of patients was 79 years (SD, 11). Male represented near half of the population. A large proportion of patients had hypertension (79.3\%).

Among patients on VKA before baseline, only $43 \%$ of patients had a TTR $\geq 70 \%$.

Among 400 patients enrolled, 31 patients died before discharge $(7.8 \%), 274$ patients belonged to the group on a 'long-term oral anticoagulant therapy' strategy $(68.5 \%)$, and 95 patients belonged to the group 'not on a long-term oral anticoagulant therapy' strategy (23.8\%) for various reasons, mainly contraindications to longterm oral anticoagulant therapy, listed in table 3 .

\section{Outcomes}

At 12 months, death or dependency occurred in $19.8 \%$ of patients on a long-term oral anticoagulant strategy and in 


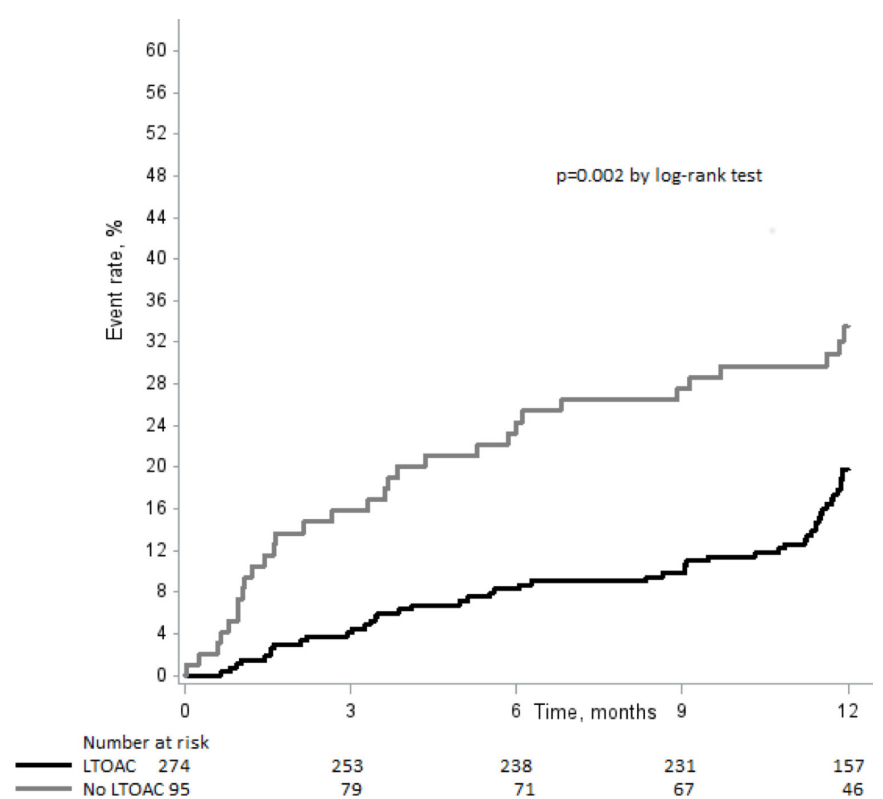

Figure 1 Twelve-month risk of death or dependency (from stroke onset to 12 months) according to treatment groups: long-term oral anticoagulant strategy (LTOAC) versus not on an LTOAC (no LTOAC).

$33.5 \%$ of patients not on a long-term oral anticoagulant strategy ( $\mathrm{p}=0.002$ ). figure 1 At 12 months, brain infarction or brain haemorrhage occurred in $9.9 \%$ of patients on a long-term oral anticoagulant strategy and in $27.2 \%$ of patients not on a long-term oral anticoagulant strategy $(\mathrm{p}<0.001)$ (table 4).

\section{Predictors of outcomes}

\section{Death and dependency}

Online supplementary table 1 shows variables associated with the risk of death or dependency in univariable analysis.

In multivariable analysis, Rankin score $\geq 2$ (almost threefold increase for mRS 2 and 3, and 14-fold increase for mRS 4 and 5), haemoglobin level, treatment groups

Table 4 Outcomes events rates according to treatment groups: long-term oral anticoagulant strategy (LTOAC) versus not on an LTOAC (no LTOAC)

\begin{tabular}{lllc}
\hline & LTOAC (n=274) & $\begin{array}{l}\text { No LTOAC } \\
(\mathbf{n = 9 5 )}\end{array}$ & P value \\
\hline $\begin{array}{l}\text { Death and dependency } \\
\text { Death }\end{array}$ & $\begin{array}{l}49(17.9) \\
39 / 49(79.6)\end{array}$ & $\begin{array}{l}31(32.6) \\
29 / 31(93.5)\end{array}$ & 0.003 \\
$\begin{array}{l}\text { Brain infarction brain } \\
\text { haemorrhage }\end{array}$ & $26(9.5)$ & $25(26.3)$ & $<0.001$ \\
\hline \multicolumn{1}{c}{ Brain infarction } & $18 / 26(69.2)$ & $15 / 25(60.0)$ & \\
\hline \multicolumn{1}{c}{ Brain haemorrhage } & $8 / 26(30.8)$ & $10 / 25(30.0)$ & \\
\hline Major bleeding & $37(13.5)$ & $19(20.0)$ & 0.13 \\
\hline Aspiration pneumonia & $35(12.8)$ & $29(30.5)$ & $<0.001$ \\
\hline Pulmonary embolism & $3(1.1)$ & $3(3.2)$ & 0.14 \\
\hline Deep venous thrombosis & $5(1.8)$ & $0(0)$ & 0.19 \\
\hline
\end{tabular}

Data are Kaplan-Meier estimates. (long-term oral anticoagulant strategy vs not on a longterm oral anticoagulant strategy), age, total cholesterol level and presence of small vessel disease (with a fourfold increase) were predictors of death or dependency (online supplementary table 2). The adjusted risk of death or dependency was onefold and half higher in patients not on a long-term oral anticoagulant strategy as compared with patients on a long-term oral anticoagulant strategy (HR 1.65; 95\% CI 1.05 to 2.61; $\mathrm{p}=0.032$ ).

\section{Recurrent brain infarction/brain haemorrhage}

Online supplementary table 3 shows variables associated with brain infarction or brain haemorrhage in univariable analysis.

In multivariable analysis, Rankin score 4 or 5 (with a fivefold increase), glucose level, haemoglobin A1C, diastolic blood pressure, abnormal aortic valve, $\mathrm{C}$ reactive protein level, presence of atherothrombosis and treatment groups were predictors of brain infarction or brain haemorrhage (online supplementary table 4).

As compared with patients on a long-term oral anticoagulant strategy, the adjusted risk of brain infarction/brain haemorrhage was twofold and half higher in patients not on a long-term oral anticoagulant strategy (HR 2.46; $95 \%$ CI 1.36 to $4.44 ; \mathrm{p}=0.003)$.

\section{DISCUSSION}

The WATCH-AF registry shows that, among patients with stroke and AF, one-fourth cannot receive a long-term oral anticoagulation strategy. One-third of these patients were dead or dependent at 12 months with an adjusted risk multiplied by 1.65 compared with patients who received a long-term oral anticoagulant strategy, and one-fourth had a recurrent brain infarction or brain haemorrhage

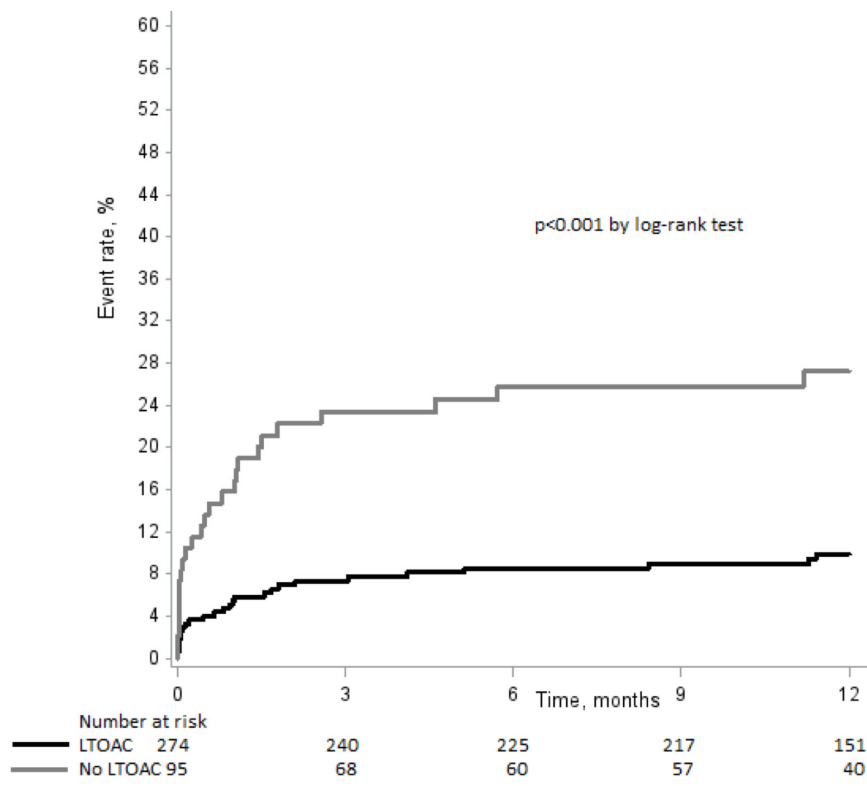

Figure 2 Twelve-month risk of brain infarction or brain haemorrhage (from stroke onset to 12 months) according to treatment groups: long-term oral anticoagulant strategy (LTOAC) versus not on an LTOAC (no LTOAC). 
with an adjusted risk multiplied by 2.5. The new finding of this prospective registry is the proportion of patients with contraindication to long-term oral anticoagulation after a stroke, based on precise assessment using scores of disability, severity, cognitive functions and functional independence after the stroke event, as well as the 1-year risk of this group. These high proportions and risks question the necessity of finding therapeutic alternatives to long-term oral anticoagulant for these patients.

Beside treatment groups, independent predictors of death or dependency included the presence of small vessel disease (either multiple small deep infarcts or severe-Fazekas III-leukoaraiosis or microbleeds) with a fourfold increase and, not surprisingly, a Rankin score more than 1 (any degree of disability) with an almost threefold increase for a discharge mRS of 2 or 3 (needing some help but functionally independent), and a 14-fold increase for a mRS of 4 or 5 (needing permanent help or bedridden). Apart from not being on a long-term oral anticoagulant strategy, discharge Rankin score 4 or 5 was also the best independent predictor of recurrent brain infarction or brain haemorrhage.

This real-life, prospective registry, without any patient selection, shows that the risk of recurrent brain infarction or brain haemorrhage is still very high, even in the group on a long-term oral anticoagulant strategy with a $9.9 \%$ annual risk, showing that beside the antithrombotic treatment, other treatment strategies need to be found to decrease this risk, including risk factors control and strategies to improve adherence to treatments such as therapeutic education programme. The $27.2 \%$ annual risk of recurrent brain infarction or brain haemorrhage in patients not on a long-term oral anticoagulant strategy strengthens the case for alternative preventive strategies in these patients to be trialled such as left atrial appendage closure. According to figure 2, this risk is maximum during the first 3-month period postindex stroke. The reasons for not being on a long-term anticoagulant strategy were patient refusal, contraindication to long-term oral anticoagulant, comorbidity, frailty, patient bedridden or with severe dementia, history of bleeding precluding a long-term oral anticoagulant strategy or adherence to treatment (table 3 ).

The strengths of this registry were that (1) both stroke centres were primary care with a dedicated catching area, (2) inclusions have been consecutive and exhaustive with systematic verification that no patient with stroke and $\mathrm{AF}$ have been missed, (3) in every individual patient we retrospectively collected information about knowledge of AF, chosen treatment strategies by their primary care physician or cardiologist, risk factor stratification including $\mathrm{CHA}_{2} \mathrm{DS}_{2}$ VASC, HAS-BLED, ATRIA, STRATIFY, IADL and about treatment adherence to VKA (eg, INR and TTR), over the previous 6 months, (4), using a high level of precision, we thoroughly evaluated patients at baseline and during a 1-year follow-up at four visits concerning concurrent underlying causes of stroke (eg, all patients had a brain MRI, extracranial and intracranial artery assessment, transthoracic and transoesophageal echocardiography) such as associated atherosclerotic disease and cerebral small vessel disease, risk stratification $\left(\mathrm{CHA}_{2} \mathrm{DS}-\right.$ ${ }_{2}$ VASC, HAS-BLED, ATRIA scores), index stroke severity (NIHSS), disability (mRS), functional independence (IADL), risk of fall (STRATIFY risk assessment tool), cognitive function (MMSE), in order to precisely determine treatment strategy according to ESC/EHRA guidelines and (5) the very large sample size for this kind of precisions.

Generalisability of this study was limited as it involved only two centres, although busy stroke centres acting as primary care centres with a dedicated catching area, however, for the kind of precision that we set up in this registry we needed highly motivated centres, and a multicentre assessment with such a precision and numerous scales would have made the registry not feasible or with a lot of missing data. Our sample size can be viewed as rather small for an $\mathrm{AF}$ cohort. However, for the precision in scales and workup that the study needed, a sample size of 400 was an enormous effort. A much larger sample size with additions of other centres could have improve the overall generalisability, but at the expense of lack of precision.

In conclusions, we found that patients with stroke and AF not suitable to a long-term oral anticoagulant strategy represented one-fourth of the cohort and that they were at a very high 1-year risk of death and dependency and of brain infarction/brain haemorrhage recurrence. Alternative treatment options, such as left atrial appendage closure, should be trialled in these patients.

Acknowledgements This study was conducted by an academic research organisation 'Charles Foix group for clinical trial and registry in stroke' at University of Paris, Paris, France.

Contributors CG collected the data, interpreted the data and wrote the first draft of the manuscript. PA designed the study, obtained funding, interpreted the data and wrote the first draft of the manuscript. HC did the statistical analysis, generated tables and figures. Other authors collected the data, revised the draft and contributed for important intellectual content of the manuscript.

Funding This study was funded by SOS-ATTAQUE CEREBRALE (a not-for-profit stroke survivors association) via an unrestrictive grant from Boston Scientific (the maker of a left atrial appendage closure device).

Competing interests NN reports the following relationships: receipt of research grants support from Pfizer, Sanofi, from The French National Research Agency and consultancy fees from Boehringer-Ingelheim, Bayer et Amgen. PA reports receipt of research grant support from Pfizer, Sanofi, Bristol-Myers-Squibb, Merck, AstraZeneca, Boston Scientific and from the French government, and consulting fees from Pfizer, BMS, Merck, Boehringer-Ingelheim, AstraZeneca, Bayer, DaiichiSankyo, Edwards, Boston Scientific, Kowa, GSK, Fibrogen, Amgen, Shin Poong, Gilead, and lecture fees from Bayer, St-Jude Medical, Amgen, Pfizer, Sanofi.

Patient consent for publication Not required.

Ethics approval The study complies with the Declaration of Helsinki, the locally appointed ethics committee has approved the research protocol (Comité de Protection des Personnes lle de France 5).

Provenance and peer review Not commissioned; externally peer reviewed.

Data availability statement Data are available on reasonable request.

Open access This is an open access article distributed in accordance with the Creative Commons Attribution Non Commercial (CC BY-NC 4.0) license, which permits others to distribute, remix, adapt, build upon this work non-commercially, and license their derivative works on different terms, provided the original work is 
properly cited, appropriate credit is given, any changes made indicated, and the use is non-commercial. See: http://creativecommons.org/licenses/by-nc/4.0/.

ORCID iD

Pierre Amarenco http://orcid.org/0000-0002-3842-1236

\section{REFERENCES}

1 Lin HJ, Wolf PA, Kelly-Hayes M, et al. Stroke severity in atrial fibrillation. The Framingham study. Stroke 1996;27:1760-4.

2 Connolly SJ, Eikelboom JW, Ng J, et al. Net clinical benefit of adding clopidogrel to aspirin therapy in patients with atrial fibrillation for whom vitamin K antagonists are unsuitable. Ann Intern Med 2011;155:579-86.

3 Marini C, De Santis F, Sacco S, et al. Contribution of atrial fibrillation to incidence and outcome of ischemic stroke: results from a population-based study. Stroke 2005;36:1115-9.

4 Kelly-Hayes M, Beiser A, Kase CS, et al. The influence of gender and age on disability following ischemic stroke: the Framingham study. $J$ Stroke Cerebrovasc Dis 2003;12:119-26.

5 Hart RG, Benavente O, McBride R, et al. Antithrombotic therapy to prevent stroke in patients with atrial fibrillation: a meta-analysis. Ann Intern Med 1999;131:492-501.

6 Ruff CT, Giugliano RP, Braunwald E, et al. Comparison of the efficacy and safety of new oral anticoagulants with warfarin in patients with atrial fibrillation: a meta-analysis of randomised trials. Lancet 2014;383:955-62.
7 Holmes DR, Reddy VY, Turi ZG, et al. Percutaneous closure of the left atrial appendage versus warfarin therapy for prevention of stroke in patients with atrial fibrillation: a randomised non-inferiority trial. Lancet 2009;374:534-42.

8 Boersma LV, Ince H, Kische S, et al. Efficacy and safety of left atria appendage closure with Watchman in patients with or without contraindication to oral anticoagulation: 1-year follow-up outcome data of the EWOLUTION trial. Heart Rhythm 2017;14:1302-8.

9 Amarenco P, Bogousslavsky J, Caplan LR, et al. The ASCOD phenotyping of ischemic stroke (updated ASCO phenotyping). Cerebrovasc Dis 2013;36:1-5.

10 Amarenco P, Albers GW, Denison H, et al. Efficacy and safety of ticagrelor versus aspirin in acute stroke or transient ischaemic attack of atherosclerotic origin: a subgroup analysis of SOCRATES, a randomised, double-blind, controlled trial. Lancet Neurol 2017;16:301-10.

11 Meier B, Blaauw Y, Khattab AA, et al. EHRA/EAPCI expert consensus statement on catheter-based left atrial appendage occlusion. Europace 2014;16:1397-416.

12 Tzikas A, Holmes DR, Gafoor S, et al. Percutaneous left atria appendage occlusion: the Munich consensus document on definitions, endpoints, and data collection requirements for clinical studies. Europace 2017;19:4-15.

13 Camm AJ, Lip GYH, De Caterina R, et al. 2012 focused update of the ESC guidelines for the management of atrial fibrillation: an update of the 2010 ESC guidelines for the management of atrial fibrillation. developed with the special contribution of the European heart rhythm association. Eur Heart J 2012;33:2719-47. 